\title{
Erratum to: Dietary and commercialized fructose: Sweet or sour?
}

\author{
Aslihan Yerlikaya $^{1} \cdot$ Tuncay Dagel $^{2} \cdot$ Christopher King $^{3} \cdot$ Masanari Kuwabara $^{3}$. \\ Miguel A. Lanaspa ${ }^{3} \cdot$ Ana Andres-Hernando $^{3} \cdot$ Adrian Covic $^{4,5} \cdot$ Jacek Manitius $^{6}$. \\ Alan A. Sag ${ }^{7}$ Mehmet Kanbay ${ }^{1,2}$ (1)
}

Published online: 5 April 2017

(C) Springer Science+Business Media Dordrecht 2017

\section{Erratum to: Int Urol Nephrol \\ DOI 10.1007/s11255-017-1544-8}

In the original publication, the fourth author's name was incorrectly published as Masanari Kubawara. The correct name should read as Masanari Kuwabara.

The original article has been updated.

The online version of the original article can be found under doi:10.1007/s11255-017-1544-8.

\footnotetext{
Mehmet Kanbay

mkanbay@ku.edu.tr; drkanbay@yahoo.com

1 School of Medicine, Koç University, Rumelifeneri Yolu, Sariyer, 34450 Istanbul, Turkey

2 Division of Nephrology, Department of Medicine, Koc University Hospital, Istanbul, Turkey

3 Division of Renal Diseases and Hypertension, University of Colorado, Denver, CO, USA

4 Nephrology Clinic, Dialysis and Renal Transplant Center, 'C.I. PARHON' University Hospital, Iasi, Romania

5 'Grigore T. Popa' University of Medicine Iasi, Iasi, Romania

6 Department of Hypertension and Internal Medicine, Nicolaus Copernicus University, Bydgoszcz, Poland

7 Division of Interventional Radiology, Department of Radiology, School of Medicine, Koç University, Istanbul, Turkey
} 